\title{
Optimizing treatment success in multiple sclerosis
}

\author{
Tjalf Ziemssen $^{1}$ (I) Tobias Derfuss $^{1} \cdot$ Nicola de $^{\text {Stefano }}{ }^{2} \cdot$ Gavin Giovannoni $^{3}$. \\ Filipe Palavra $^{4} \cdot$ Davorka Tomic $^{5} \cdot$ Tim Vollmer $^{6} \cdot$ Sven Schippling $^{7}$
}

Received: 5 September 2015 / Accepted: 25 November 2015/Published online: 24 December 2015

(C) The Author(s) 2015. This article is published with open access at Springerlink.com

\begin{abstract}
Despite important advances in the treatment of multiple sclerosis (MS) over recent years, the introduction of several disease-modifying therapies (DMTs), the burden of progressive disability and premature mortality associated with the condition remains substantial. This burden, together with the high healthcare and societal costs associated with MS, creates a compelling case for early treatment optimization with highly efficacious therapies. Often, patients receive several first-line therapies, while more recent and in part more effective treatments are still being introduced only after these have failed. However, with the availability of highly efficacious therapies, a novel treatment strategy has emerged, where the aim is to achieve no evidence of disease activity (NEDA). Achieving NEDA
\end{abstract}

Tjalf Ziemssen

Tjalf.Ziemssen@uniklinikum-dresden.de

1 MS Center Dresden, Center of Clinical Neuroscience, Neurological Clinic, University Hospital Carl Gustav Carus, Dresden University of Technology, Fetscherstrasse 74, 01307 Dresden, Germany

2 Department of Medicine, Surgery and Neuroscience, University of Siena, Siena, Italy

3 Queen Mary University London, Barts and The London School of Medicine and Dentistry, London, UK

4 Neurology-Neuroimmunology Department, Multiple Sclerosis Centre of Catalonia (Cemcat), Vall d'Hebron University Hospital, Barcelona, Spain

5 Novartis Pharma AG, Basel, Switzerland

6 University of Colorado Health Sciences Center, Aurora, CO, USA

7 Department of Neurology, Neuroimmunology and Multiple Sclerosis Research, University Hospital Zurich, University of Zurich, Zurich, Switzerland necessitates regular monitoring of relapses, disability and functionality. However, there is only a poor correlation between conventional magnetic resonance imaging measures like T2 hyperintense lesion burden and the level of clinical disability. Hence, MRI-based measures of brain atrophy have emerged in recent years potentially reflecting the magnitude of MS-related neuroaxonal damage. Currently available DMTs differ markedly in their effects on brain atrophy: some, such as fingolimod, have been shown to significantly slow brain volume loss, compared to placebo, whereas others have shown either no, inconsistent, or delayed effects. In addition to regular monitoring, treatment optimization also requires early intervention with efficacious therapies, because accumulating evidence shows that effective intervention during a limited period early in the course of MS is critical for maintaining neurological function and preventing subsequent disability. Together, the advent of new MS therapies and evolving management strategies offer exciting new opportunities to optimize treatment outcomes.

Keywords Brain atrophy - Disability evaluation . Drug therapy $\cdot$ Multiple sclerosis

\section{Introduction}

Although recent years have seen great advances in the treatment of multiple sclerosis (MS), with an increasing number of disease-modifying therapies (DMTs) becoming available, it remains a potentially serious and debilitating condition as none of the current treatments halts or cures the disease. A broad range of neurological functions may be affected, including vision, gait and motor function, cognition, coordination, and balance, as well as bladder, 
bowel and sexual function [1]. Cognitive impairment, for example, is present in up to $82 \%$ of patients with MS [25]: it can be detected in the earliest stages of the disease [5], and adversely affects employment, activities of daily living, and social function [3, 6, 7]. Furthermore, in most cases, MS causes progressive disability, which can involve both motor and cognitive function and has a detrimental impact on patients' quality of life [8]. Indeed, there is evidence that the impact of MS-related fatigue, unemployment and limited mobility on quality of life is greater than that associated with other causes of disability $[9,10]$. MS-related disability is a major driver of the substantial healthcare and social costs associated with the condition [7]: European [11] and US [9, 12] data suggest that approximately $40-44 \%$ of total MS-related costs result from lost productivity.

In addition to the physical and cognitive impairment associated with MS, life expectancy in people with MS is on average 8-12 years shorter than in the general population [13-16]. Up to approximately $78 \%$ of people with MS die of disease-related complications such as respiratory tract infections or accidents [16-19]. This burden of disability and premature mortality, and the substantial economic costs associated with the condition, create a compelling case for early intervention and early treatment optimization with the more efficacious treatments that are now becoming available. At present, it is common practice in many countries for patients to receive several first-line therapies, such as interferon (IFN)- $\beta$, glatiramer acetate, teriflunomide or dimethyl fumarate (DMF), before therapies with greater efficacy, such as fingolimod, natalizumab or alemtuzumab, are tried following failure of these firstline agents [20]. However, there is increasing evidence that both early intervention after diagnosis, and early treatment optimization in the event of insufficient response to initial treatment (Fig. 1), are critical to achieving a favourable outcome and reducing the progressive burden imposed by MS on the patients, their families, and society as a whole [21].

The question of how best to intervene early in MS in order to achieve an optimal outcome was discussed at a round-table meeting in Barcelona, Spain, in June 2013. The key outcomes from this meeting are summarized in this paper.

\section{Monitoring disease activity in multiple sclerosis}

Monitoring MS disease activity is key to achieving optimal outcomes. However, the heterogeneity of the disease, and the complexity of the underlying biological mechanisms, can render this challenging. MS pathology is characterized by two major hallmarks: inflammation and

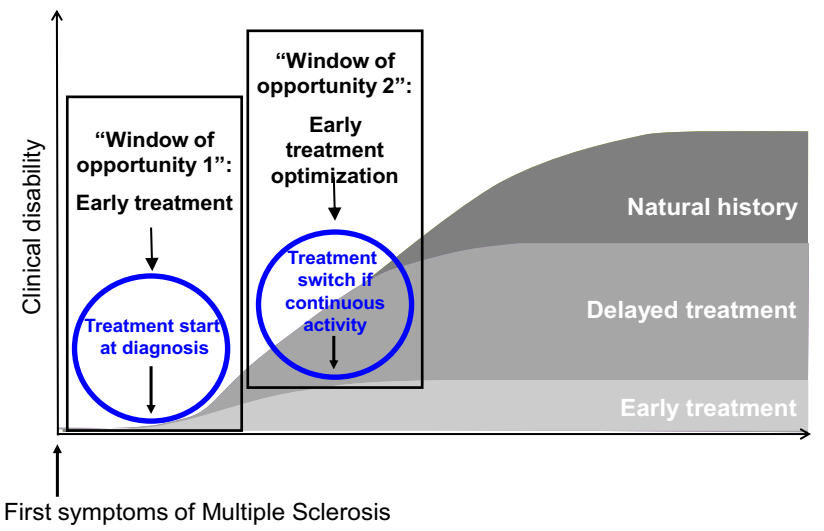

Fig. 1 The 'windows of opportunity' for treatment optimization in MS. Early initiation of treatment, and prompt intervention if disease activity persists despite initial treatment, are both critical to optimizing treatment outcomes. In both cases, there is only a limited period during which intervention will be effective. Adapted with permission from Tintoré [22]

progressive neuroaxonal damage [23-27]. From a clinical perspective, inflammation is infrequently associated with the subacute onset of clinical signs and symptoms and focal lesions on magnetic resonance imaging (MRI) that usually show temporary permeability of the blood-brain barrier, reflected by contrast enhancement at sites of acute inflammation. By contrast, axonal degeneration and loss of neurons are associated with sustained disability and evidence of brain or spinal cord atrophy on MRI over time (Fig. 2) [28]. Axonal transection is a consistent pathological feature of acute MS lesions, and the incidence of neuronal damage correlates with the extent of inflammation within the lesion [25]. Importantly, such damage may be present in the early stages of MS [27]. It can, however, be masked by mechanisms such as recruitment of other neuronal pathways or cortical remodelling, that compensate for functional loss; hence, progressive damage may go unrecognized until it is too late for an intervention to be

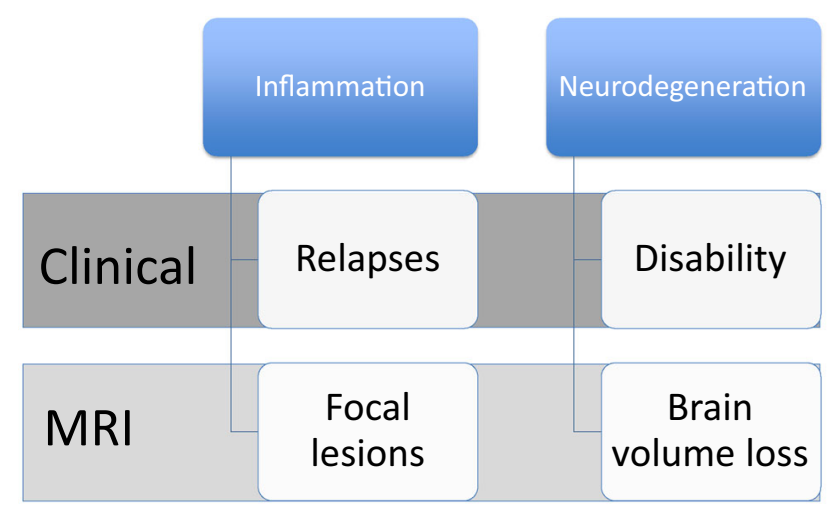

Fig. 2 Associations between inflammatory and degenerative processes in MS and the clinical and MRI features of the disease 


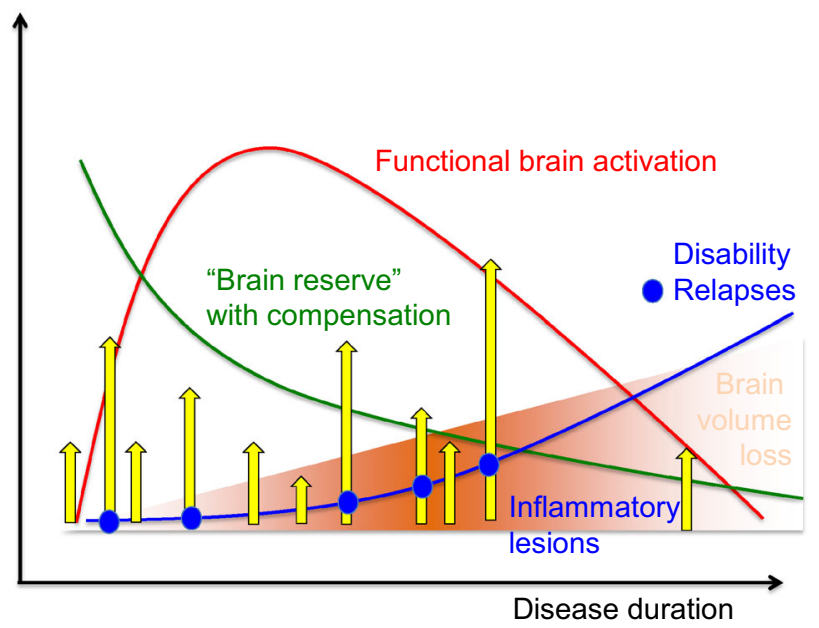

Fig. 3 The relationship between relapses, inflammation and disability in MS. The disease process in MS is characterized by both inflammation and progressive neuroaxonal damage. Importantly, such damage may be present in the early stages of MS, but may be masked by compensatory mechanisms; hence, progressive damage may go unrecognized until it is too late for intervention to be beneficial. As the disease progresses, the balance between degenerative and reparative processes shifts, resulting in progressive neuroaxonal degeneration and increasing disability

beneficial $[29,30]$. As the disease progresses, the balance between degenerative and reparative processes shifts, resulting in progressive neuroaxonal degeneration and increasing disability (Fig. 3). Hence, clinical disease monitoring in MS should have three elements: disease activity as manifested in relapses (reflecting inflammation), disability (reflecting neuroaxonal loss) and functionality (reflecting the degree of compensation or cerebral reserve) (Fig. 4)

\section{Monitoring MS by clinical parameters: relapses versus disability}

In the majority of MS patients, the disease initially takes a relapsing-remitting course (RRMS), characterized by acute symptomatic relapses followed by periods of variable recovery. In the absence of treatment, more than $50 \%$ of patients with RRMS will develop progressive disability after approximately 15 years [31].

Natural history studies have provided important insights into the determinants of disability progression in early MS. One such study showed a significant association between relapses occurring in the early stages of MS and long-term disability, which was primarily driven by an increasing risk of SPMS and, to a lesser extent, by an effect of frequent relapses on the rate of progression [32]. A further study [33] found that age at onset of MS, residual deficits after a first relapse, and the number of relapses during the first 2 years

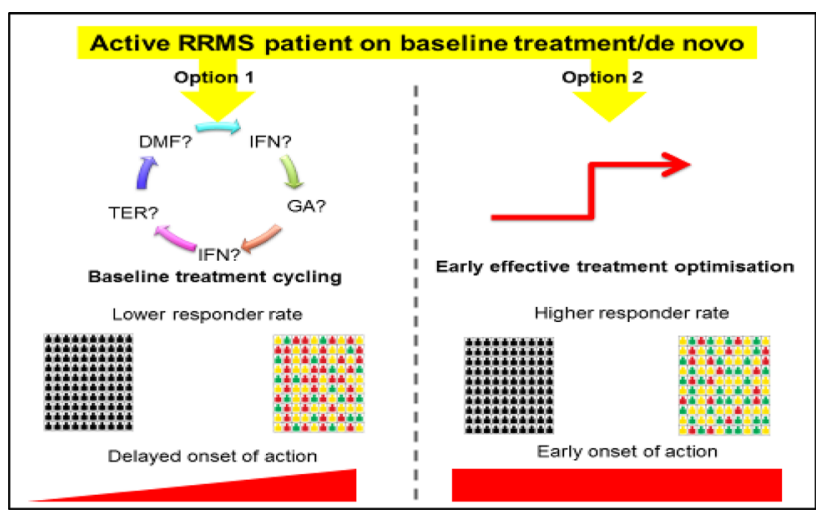

Fig. 4 Potential treatment strategies in MS. In patients with little evidence of disease activity at baseline, treatment can be started with conventional first-line therapies such as IFN- $\beta$, glatiramer acetate, DMF or teriflunomide. Treatment should be monitored every 6-12months. For patients with highly active disease at baseline or rapidly evolving severe disease ( $\geq 2$ disabling relapses in 1 year, with at least one $\mathrm{Gd}+$ lesion on T1-weighted MRI or a significant increase in lesion load on T2-weighted MRI), newer agents can be used as firstline therapy. The main differences between these two strategies are the higher responder rate and the earlier onset of action with the latter, which has to be evaluated for each individual patient

were predictive of the time to a Disability Status Score (DSS) of 3 (moderate disability), but not of the time from DSS 3 to DSS 6 (requiring assistance to walk). The authors suggested that these findings would be consistent with a two-phase process of progressive disability, in which the first stage is related to focal inflammation that is amenable to treatment, whereas the second stage is independent of current inflammation and may be related to diffuse neurodegeneration [33].

\section{Monitoring MS by MRI: inflammatory activity versus destructive markers}

Conventional MRI techniques, such as T2-weighted imaging and gadolinium (Gd)-enhanced T1-weighted imaging (Table 1) offer good sensitivity in assessing the location and temporal evolution of demyelinating plaques in the brain and spinal cord of MS patients; indeed, these techniques are considered to represent the 'gold standard' for diagnosing MS and monitoring the response to treatment $[31,34]$. However, due to the limited pathological specificity of these techniques, they provide little information about the underlying inflammatory process in MS, and show only weak correlations with clinical measures of disability [31, 34].

Alternatively, this apparent lack of correlation between conventional MRI measures and clinical disability could also be due to the low sensitivity of clinical measures of disability applied in routine clinical practice. For example, the widely used Expanded Disability Status Scale (EDSS) reflects the level of damage that has already occurred, and 
Table 1 Conventional and emerging techniques used in the assessment of MS [34]

\begin{tabular}{ll}
\hline Technique & Role in MS \\
\hline Gd-enhanced T1-weighted imaging & $\begin{array}{l}\text { Identification of demyelinated lesions (hypointense } \\
\text { loci) }\end{array}$ \\
T2-weighted imaging & $\begin{array}{l}\text { Identification of demyelinated lesions (hyperintense } \\
\text { loci) }\end{array}$ \\
2- and 3-dimensional fluid-attenuated & $\left\{\begin{array}{l}\text { Identification of cortical, periventricular and } \\
\text { inversion recovery (FLAIR) }\end{array}\right.$ \\
sequences & $\begin{array}{l}\text { Detection of subpial cortical and deep grey matter } \\
\text { Double inversion recovery sequences }\end{array}$ \\
Ultra-high field strength MRI & $\begin{array}{l}\text { lesions } \\
\text { Detection of hypointense black holes, a measure of } \\
\text { chronic neurodegeneration }\end{array}$ \\
Unenhanced T1-weighted imaging & Characterization of the evolution of MS lesions and \\
normal-appearing brain tissue \\
Magnetization transfer imaging \\
(MTI)
\end{tabular}

Several studies have shown that, at a group level, brain atrophy in MS patients appears to be predictive of subsequent disability [40, 41]. Indeed, it has been suggested that measurement of brain atrophy may be the best predictor of subsequent disability in MS patients [37, 42, 43]. Although atrophy affects both grey and white matter regions of the brain $[37,42]$, there is evidence that grey matter (cortical and deep grey matter) atrophy is more closely related to long-term disability than white matter atrophy. In one study, for example, grey matter atrophy showed significant correlations with disability measured either by the EDSS or the MS functional composite (MSFC), whereas no such correlations were seen with white matter atrophy; furthermore, changes in the grey matter fraction accounted for a greater proportion of the variability in clinical findings than changes in white matter [44]. Importantly, a recent pathological study has shown that plaque-like primary demyelinating cortical lesions are specific to MS, and are not seen in other neuroinflammatory disorders such as tuberculous meningitis or chronic purulent meningitis [45].

Recent studies have shown that the combination of brain atrophy measures and MRI lesion load is a strong predictor of long-term disability. In a study of 261 MS patients in whom EDSS assessments were available at baseline and after 10 years' follow-up, and in whom MRI investigations 
Table 2 Immediate and delayed treatment effects on brain volume changes in the double-blind phases of trials of disease-modifying therapies in RRMS [48-70]

\begin{tabular}{|c|c|c|c|c|}
\hline Drug & Numbers of patients & $\begin{array}{l}\text { Global effect on brain } \\
\text { volume }\end{array}$ & $\begin{array}{l}\text { Immediate effect on brain } \\
\text { volume }\end{array}$ & $\begin{array}{l}\text { Delayed effect on brain } \\
\text { volume }\end{array}$ \\
\hline \multicolumn{5}{|l|}{ Placebo-controlled studies } \\
\hline Interferon $\beta$-1a [48-51] & 172,382 & No & No & Yes \\
\hline Glatiramer acetate [52-55] & $\begin{array}{l}27 \text { (subcohort), 207, } \\
980\end{array}$ & No & $\mathrm{No}^{\mathrm{a}}$ & $\mathrm{NA}^{\mathrm{b}}$ \\
\hline Fingolimod [56-58] & 1033,1153 & Yes & Yes & Yes \\
\hline Dimethyl fumarate $[59,60]$ & 540,681 & $\mathrm{Yes}^{\mathrm{c}}$ & $\mathrm{No}^{\mathrm{d}}$ & Yes $^{\mathrm{d}}$ \\
\hline Teriflunamide [63] & 1074 & No & No & No \\
\hline Laquinimod $[64,65]$ & 1106,1331 & Yes & NA & NA \\
\hline Natalizumab $[61,62]$ & 942,1003 & No & No & Yes \\
\hline \multicolumn{5}{|l|}{ Active comparator studies } \\
\hline $\begin{array}{l}\text { Interferon versus glatiramer acetate } \\
\text { [66-68] }\end{array}$ & 460, 1008, 2096 & Yes $(\mathrm{GA})^{\mathrm{e}}$ & Yes $(\mathrm{GA})^{\mathrm{e}}$ & Yes $(\mathrm{GA})^{\mathrm{e}}$ \\
\hline $\begin{array}{l}\text { Fingolimod versus im IFN } \beta \text {-1a } \\
\text { [57] }\end{array}$ & 1153 & Yes (FTY) & Yes (FTY) & $N A^{f}$ \\
\hline $\begin{array}{l}\text { Alemtuzumab versus sc IFN } \beta \text {-1a } \\
{[69,70]}\end{array}$ & $334,581,840$ & Yes (AL) & $\mathrm{NA}^{\mathrm{g}}$ & $\mathrm{NA}^{\mathrm{g}}$ \\
\hline
\end{tabular}

Adapted from Vidal-Jordana et al. [48]

$A L$ alemtuzumab, IFN interferon, im intramuscular, $G A$ glatiramer acetate, $N A$ not applicable, $s c$ subcutaneous

a Baseline to 9 months

b Open-label data: a significant effect of glatiramer acetate was observed in months 9-18 in the early treatment arm

c Only for twice-daily dosing in the DEFINE trial; brain volume was assessed during the 6-24 month period

d Only for twice-daily dosing in the CONFIRM trial: no data available for the DEFINE trial

${ }^{\mathrm{e}}$ Data only from the REGARD trial, no $P$ values reported; no significant differences were observed in the BEYOND AND COMBIRx trials

${ }^{\mathrm{f}}$ No data available beyond 12 months

g The two CARE-MS trials only assessed brain volume changes from baseline to 24 months

were performed over 1-2 years after baseline, the combination of these MRI measures was strongly predictive of EDSS scores after 10 years $\left(R^{2}=0.74\right)$; furthermore, central atrophy was predictive of long-term disability in patients with minimal impairment (EDSS 0-3.5) at baseline, whereas $\mathrm{T} 2$ lesion volume was predictive in patients with moderate impairment (EDSS 4-6) at baseline [46].

A recent meta-analysis, including data from more than 13,500 patients enrolled in 13 randomized controlled trials, has investigated the relationship between changes in brain atrophy and disease progression during treatment of RRMS [47]. Treatment effects on both brain atrophy and active MRI lesions (defined as new or enlarging T2 lesions) were significantly and independently correlated with effects on disability progression at group level, and the correlation was strongest when both MRI endpoints were included in a multivariate model.

The available DMTs appear to differ in their effects on brain atrophy (Table 2) [36, 50-70], although it should be noted that direct comparisons are difficult between trials because of the heterogeneity of patient populations and methods applied to measure brain volume used in different studies. During treatment with many DMTs, an apparent decrease in brain volume (pseudoatrophy) occurs during the first 6-9 months, but a significant decrease in atrophy rate, compared with placebo, occurs during the second year of treatment with some agents $[56,61,63$, 71-77].

At present, brain atrophy is not measured routinely in MS centres and is not used to monitor treatment. Hence, the use of brain atrophy as an outcome measure in MS will require standardization of MRI acquisition and post-processing procedures to allow comparisons of scans obtained at different times during the course of MS and at different centres. In clinical trials, brain volume should be measured at 3-6 month intervals to identify pseudoatrophy [78, 79], while in routine clinical practice scans should be taken 6 months after starting DMTs to establish a baseline for assessments of brain atrophy that is less likely confounded by pseudoatrophy effects. SIENA (Structural Image Evaluation, using Normalization, of Atrophy), usually used to measure brain volume loss in clinical trials, could 
potentially be incorporated into MS management but would still necessitate a technology and staff infrastructure not necessarily available in MS centers. However, other simpler techniques such as measurement of third ventricular width, lateral ventricle volume and corpus callosum index might provide alternative options once validated in clinical routine [37, 42, 80, 81].

\section{Monitoring MS by patient-reported outcomes}

From a patient's perspective, a treatment may be considered to be a failure if it produces adverse events that affect everyday quality of life. This would suggest that worsening in patient-reported outcomes related to fatigue, depression, cognitive dysfunction, mobility, sexual function or bowel/ bladder function should also be included in definitions of treatment failure [1]. Similarly, in view of the significant impact of MS-related disability on quality of life [8], changes in quality of life should be considered an important outcome in MS treatment (Fig. 4).

It may be anticipated that patient-reported outcomes will become increasingly important in MS management as the focus of treatment moves to the prevention or delay of disability, rather than clinical relapses or MRI measures of disease activity [82]. It will therefore be necessary to validate such outcome measures in clinical trials and routine practice [83]. A recent study has found that two widely used outcome measures, the MS Impact Scale (MSIS-29) and the Hamburg Quality of Life Questionnaire in MS (HAQUAMS), are able to differentiate between MS patients with different degrees of functional impairment, with moderate correlations between these instruments and conventional disability measures such as the EDSS and the MSFC [84].

\section{Combining monitoring strategies in MS treatment: the NEDA concept}

As noted above, current practice in MS is to start with firstline therapies and then introduce more efficacious agents if the response is inadequate or if first-line therapy is poorly tolerated [19]. This approach is enshrined in current MS management guidelines from a number of European countries [85, 86]. In recent years, however, a new strategy has emerged, 'treating to target,' where the aim is to achieve no evidence of disease activity (NEDA). This may be defined as absence of relapses, disability progression and MRI measures of disease activity including new Gadolinium enhancing and new or newly enlarging T2 lesions [87]. There is evidence that MS patients treated to target of NEDA have better outcomes than those with clinical or subclinical breakthrough disease, and hence it has been recommended by some that this approach should be incorporated into routine clinical practice [88]. A recent long-term (up to 7 years) study found that NEDA status at 2 years had optimal prognostic value, although NEDA was difficult to sustain over the longer term, even with treatment [89]. In this study, NEDA was defined as a composite of absence of relapses, no EDSS progression and no new or enlarging T2 or T1 Gd-enhancing lesions on annual MRI. However, it has been argued that such a focus on clinical and MRI measures does not adequately reflect patients' needs in routine clinical practice [90].

In view of such considerations, it is anticipated that the definition of NEDA is likely to evolve as evidence accumulates to support the incorporation of additional outcome measures [88]. For example, there is increasing evidence that the absence of brain atrophy, as measured by MRI, may also be a valid criterion for NEDA. This view is based on the evidence, discussed above, that measures of brain atrophy, despite methodological limitations, appear to be a clinically useful marker of neuroaxonal damage in MS; indeed, early brain atrophy has recently been shown to be predictive of response to IFN- $\beta$ treatment [91]. The combination of relapses, disability progression and conventional MRI measures with assessment of brain volume loss has been termed NEDA-4 [92]. In an analysis of two pivotal trials with fingolimod, the addition of brain volume loss increased the stringency of the NEDA measure without affecting the sensitivity of the measurement to treatment effects [92]. However, regular MRI monitoring of brain volume may not be currently feasible in routine clinical practice due to limited availability of the technological infrastructure and trained staff as indicated above.

The increasing focus on NEDA as an aim of MS therapy implies that regular, systematic, monitoring should be a central aspect of the management of the condition, and this is reflected in recent Canadian guidelines that recommend the implementation of MRI monitoring, ultimately advocating implementation of NEDA-4 as an aspirational goal [93]. These guidelines recommend regular MRI follow-up, beginning at 3-6 months after initiation of treatment, at 6-12 months after the reference scan and annually thereafter [93].

\section{The importance of early diagnosis and early treatment in MS}

Evidence is accumulating to support the assumption that there is a period early in the course of MS during which treatment is most efficacious, and that effective treatment during this period appears to be critical for maintaining long-term neurological function and preventing subsequent disability and premature mortality over the lifetime of the patient. 
Several clinical trials have provided proof of concept for an early window of first treatment intervention in clinically isolated syndrome (CIS). Results from the 2-year blinded phase of the BENEFIT study [94] in patients with a first event suggestive of MS showed that the time to confirmed progression on the EDSS was significantly longer in those receiving early treatment than in those who were on placebo, and so had a delayed start of treatment, and the risk of progression was reduced by $40 \%$ [hazard ratio (HR) $0.60,95 \%$ confidence interval (CI) $0.39-0.92, P=0.022]$. The authors noted that, although the delay in treatment was equivalent to just a single clinical event, this was nevertheless sufficient to influence the subsequent accumulation of disability, and that the delay in progression associated with early treatment could be considered to be clinically relevant [94]. A subsequent analysis after 5 years of follow-up showed that the rate of progression to clinically definite MS was significantly lower with early treatment than with delayed treatment, although the risk of confirmed progression of disability did not differ between the groups and mean EDSS scores were low [73]. Other IFN- $\beta$ studies [95-99] showed that, compared with placebo, early intervention significantly reduced the risk of progression to clinically definite MS in patients with a first clinical event suggestive of MS, and similar results have been obtained with glatiramer acetate [100] and teriflunomide [101].

Further evidence for a critical period for early intervention in MS comes from a study with alemtuzumab, which involved both an SPMS and an RRMS cohort [102]. The mean $( \pm \mathrm{SD})$ disease duration at the start of alemtuzumab treatment was $11.2 \pm 6.1$ years in the secondary progression cohort, of which an average of $3.6 \pm 2.6$ years had been spent in the progressive phase, whereas in the RRMS group the mean duration of disease prior to treatment was $2.7 \pm 2.9$ years. In the RRMS cohort, treatment with alemtuzumab significantly reduced relapse rates, prevented the accumulation of disability, and allowed some patients to recover function as measured by the EDSS; by contrast, in patients with SPMS alemtuzumab suppressed inflammation and slowed (but did not prevent) progressive disability, and there was little recovery of function. These findings were attributed by the authors to the beneficial effects of early rescue of neurons from an inflammatory environment [102]. Additional evidence comes from the results of an extension phase to the FREEDOMS study, in which patients who received placebo during the doubleblind phase were switched to fingolimod. Although these patients showed significant clinical improvements, including reductions in relapse rates, disability progression and brain atrophy, following initiation of fingolimod, these benefits were less marked than in patients who received fingolimod treatment from the start of the study [103].

\section{Early treatment optimization}

\section{MRI lesions and clinical endpoints}

A recent 15-year follow-up study of RRMS patients who received IFN- $\beta$-1a during a pivotal clinical trial has shown that the presence of at least two Gd-enhancing lesions over the 2-years of treatment in the IFN arm of the study was strongly predictive of EDSS worsening [104]. In a further study, the presence of two or three measures of disease activity (new MRI lesions, relapses or confirmed 1-point EDSS progression) during the first year of IFN- $\beta$ treatment was predictive of a subsequent poor response to therapy [105].

A scoring system for MS disease activity was described by Río et al. [106], who analysed data from 222 patients with RRMS who had received IFN- $\beta 1$ a for at least 1 year. This system was based on measurements of clinical relapses, disability progression (increase of 1 EDSS point confirmed at 6 months) and active MRI lesions ( $\geq 2$ new $\mathrm{T} 2$ or Gd-enhancing lesions) 1 year after the start of treatment. Patients who met at least two of these criteria were more likely to experience progressive disability or relapses during the subsequent 2 years than those who did not. However, relapses or MRI criteria alone were not predictive of new disease activity or disease progression. By contrast, Prosperini et al. [107] found that the 4-year outcomes of patients with isolated MRI activity after the first year of IFN- $\beta$ therapy did not differ from those fulfilling the European Medicines Agency (EMA) criteria for second-line treatment escalation. This would suggest that MRI alone might be a good predictor of outcome.

A modified version of the Río scoring system has recently been published, based on relapses and focal MRI activity only [108, 109]. Validation of this system in the dataset used to develop the original Río system resulted in a $24 \%$ probability of disease progression in patients considered to be at low risk of progression, a $33 \%$ probability in medium-risk patients, and a $65 \%$ probability in highrisk patients; a subsequent study showed that more efficient classification of medium-risk patients could be achieved by further MRI and clinical evaluation 6 months after the first year of therapy [110].

In a long-term (16 years) retrospective follow-up of a pivotal IFN- $\beta$ trial, baseline EDSS scores correlated with both physical and cognitive outcome $\left(R^{2}=0.22\right.$ and 0.12 , respectively, $P<0.0001$ for both), while accumulation of disability during the course of the study correlated significantly with physical outcome $\left(R^{2}=0.11, P<0.0001\right)$, but not with cognition [111]. By contrast, baseline MRI measures of atrophy and lesion burden correlated with cognitive outcome $\left(R^{2}=0.21, P<0.0001\right)$, but not with 

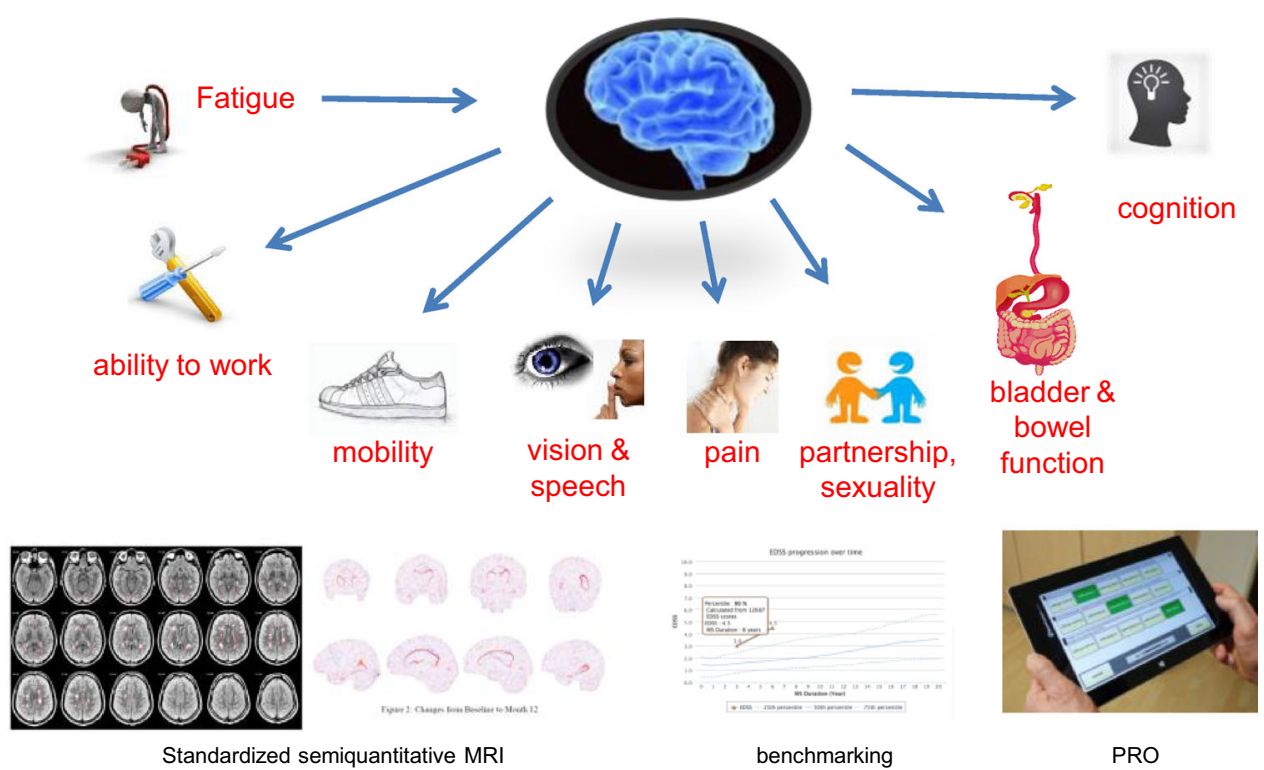

Fig. 5 Assessment of patients at risk of disease progression or treatment failure will require attention to both traditional outcome measures, such as relapses and disability, and to newer measures such as MRI assessments of brain atrophy and patient-reported outcomes
(PROs). This in turn will require benchmarking to establish baseline levels of disability, allowing longitudinal assessments of disability over time, and standardized MRI protocols to monitor treatment effects on brain atrophy physical outcome. These findings offer support for the hypothesis that long-term outcome in MS is influenced at least in part by disease activity during the initial years of the disease.

The growing evidence, discussed above, that there is only a limited window of opportunity for effective intervention in MS with currently available drugs would suggest that regular monitoring during treatment with DMTs, and prompt intervention in cases of suboptimal response or treatment failure, are essential to prevent long-term disability. (Although it should be noted that the impact of early treatment switching has, to date, been studied only in patients receiving IFN- $\beta$.) As described previously, at present it is common for a patient to receive several firstline therapies, with escalating doses or treatment switches if the responses are inadequate, before more efficacious therapies are tried [20]. The available evidence suggests that switching to a different class of DMT (either as another first-line therapy or as second-line treatment) is more effective than dose escalation or switching to another member of the same class [83, 84, 112-117]. For example, in the CARE-MS II study, treatment with alemtuzumab reduced relapse rates and disability in RRMS patients who had previously experienced at least one relapse during firstline treatment with IFN $\beta$-1a or glatiramer acetate [117]. However, there is also evidence that initiating treatment with newer agents may be more effective than introducing these agents as second-line treatment. For example, in a randomized extension to the TRANSFORMS study, patients who received fingolimod from the start of the trial showed better clinical and MRI outcomes than those originally randomized to IFN- $\beta-1 \mathrm{a}$ and subsequently switched to fingolimod during the extension phase [118]. Currently, highly effective DMTs such as fingolimod, natalizumab and alemtuzumab are mainly licensed for the first-line treatment of patients with highly active MS; further clinical data, including cost-effectiveness data, will be needed to support the early use of such therapies [119].

Based on the evidence currently available, a number of potential strategies for the management of MS can be defined, depending on the level of disease activity (Fig. 5). In patients with little evidence of disease activity at baseline, treatment can be started with conventional first-line therapies such as IFN- $\beta$, glatiramer acetate, DMF or teriflunomide. Treatment should be monitored at 6-12-month intervals, and highly effective agents such as fingolimod, natalizumab, or alemtuzumab substituted (subject to their licensing conditions) if signs of disease activity such as frequent relapses, increasing disability, or worsening MRI lesion burden (and possibly brain atrophy) are observed. For patients with highly active disease at baseline or rapidly evolving severe disease ( $\geq 2$ disabling relapses in 1 year, with at least one $\mathrm{Gd}+$ lesion on T1-weighted MRI or a significant increase in lesion load on T2-weighted MRI), newer agents can be used as first-line therapy, and treatment monitored to ensure that NEDA is achieved. 
While these strategies focus on clinical and MRI measures of disease activity, it should be noted that patient-reported progression of symptoms, adverse effects of treatment, and an inability to tolerate injections may also constitute grounds for switching treatments. There are currently no data to suggest that the early use of effective treatments presents a risk of 'therapeutic burn-out.' Rather, the clear evidence for a limited therapeutic window militates in favour of early intervention and treatment optimization. The increasing number of highly active treatments becoming available raises the possibility of sequential treatment where necessary.

\section{Conclusions}

The introduction of highly effective treatments, such as fingolimod, natalizumab and alemtuzumab, has considerably expanded treatment options in MS. At the same time, the choice of treatment has assumed a new importance for a number of reasons. In particular, there is strong evidence that there is a limited time window to intervene effectively in patients with early MS, and that intervention during this period appears to be critical for achieving favourable longterm outcomes. Furthermore, a new therapeutic strategy, treating to target to achieve no evidence of disease activity, has emerged, and this may entail preservation of brain tissue in addition to the traditional endpoints of clinical relapses and MRI measures of inflammation. Importantly, treating to target necessitates regular monitoring of disease activity to allow prompt switches in cases of treatment failure.

Effective intervention during the window of opportunity requires identification of, and prompt response to, suboptimal response or treatment failure. However, it is difficult to define treatment failure adequately because much disease activity in MS (particularly during the early stages) is subclinical, and hence it is not usually possible to be sure that no disease activity is present and long-term consequences are-at least in part-unknown. It is therefore necessary to look for the best outcomes in groups of patients included in clinical trials in order to identify the most effective therapies. As emphasized above, it will also be necessary to monitor treatment with DMTs systematically and consistently in order to identify suboptimal response or treatment failure promptly. This will necessitate attention both to traditional clinical endpoints such as relapses and disability (with benchmarking of baseline levels of disability), and to newer outcome measures such as brain atrophy (measured using standardized MRI protocols, cognition and patient-reported outcomes (Fig. 5). The regular assessment of the patient can be supported by a computerized patient management system including PRO assessment, such as the MSDS 3D system [120], participation in registries which provide bench marking function, and standardized semi-quantitative MRI.

The evolving MS landscape, in which a number of new treatments are appearing — each with their own benefits and risks-will require a change in the nature of interactions between patients and their physicians, with a shared approach to clinical decision making that emphasizes patient-related goals. Together, these innovations in MS management offer exciting new opportunities to optimize treatment outcomes.

\section{Compliance with ethical standards}

Conflicts of interest All of the authors were participants in a round table meeting which took place in Barcelona, Spain, in June 2013. This meeting was funded by Novartis Pharma AG. Medical writing and editorial assistance in the development of this paper was provided by Michael Shaw PhD (Anagram Communications, UK), and funded by Novartis Pharma AG. There is no relevant conflict of interest for all authors. Tjalf Ziemssen has received reimbursements for participation in scientific advisory boards, research support and speaker honorarium from Almirall, Bayer Healthcare, Biogen, Novartis Pharma AG, Merck Sharp \& Dohme Merck Serono, Teva, Genzyme, and Synthon. Tobias Derfuss is a member of scientific advisory boards for Biogen Idec, Novartis Pharma, Genzyme, Merck Serono, Bayer Schering, Octapharma, GeNeuro, Roche, and has received travel funding and speaker honoraria from Bayer Schering, BiogenIdec, Merck Serono, Novartis Pharma, Genzyme. He is a member of the editorial board of Plos One, steering committees by Mitsubishi Pharma, Novartis Pharma, and GeNeuro, and the executive board of ECTRIMS. He has received research support from Novartis Pharma, Merck Serono, Biogen-Idec, Swiss National Foundation, European Union, and the Swiss MS Society. Nicola Di Stefano has received honoraria from Schering, Biogen-Idec, Teva, Novartis, Genzyme, and Merck Serono SA for consulting services, speaking and travel support. He serves on advisory boards for Merck Serono SA and Novartis, and has received research grant support from the Italian MS Society. Gavin Giovannoni has received compensation for serving as a consultant or speaker for, or has received research support from, AbbVie, Bayer Schering Healthcare, Biogen Idec, Canbex, Eisai, Elan, Five Prime Therapeutics, Genzyme, Genentech, GlaxoSmithKline, Ironwood Pharmaceuticals, Merck-Serono, Novartis, Pfizer, Roche, Sanofi-Aventis, Synthon BV, Teva Pharmaceutical Industries, UCB and Vertex Pharmaceuticals. Filipe Palavra received speaking honoraria and travel expenses for scientific meetings from Bayer Healthcare, Biogen, Merck Serono, Novartis Pharma, Sanofi and Teva Pharmaceuticals. Davorka Tomic is an employee of Novartis Pharma AG, Basel, Switzerland. Timothy Vollmer has received reimbursements and honorarium for participation in scientific advisory boards and research support from Abbvie, Acorda, Avanir, Biogen, Congrex, Consortium of MS Centers, DeltaQuest, EMD Serono, Genentech, Genzyme, Janssen Research, Krog \& Partners, MedImmune, NIH, Novartis, Novartis Canada, Novartis Japan, Ono, Oxford Pharmagenesis, Roche, Rocky Mountain MS Center, Teva, Vaccinex, Xenoport. Sven Schippling has received consulting or speaker fees and travel support from Bayer Healthcare, Biogen, Genzyme, Merck Serono, Novartis, Sanofi and TEVA, and has received research support from Bayer Healthcare, Biogen, Genzyme and Novartis. He is supported by the Betty and David Koetser Foundation for Brain Research, the Swiss MS Society and the Clinical Research Priority Programme of the University of Zurich. 
Open Access This article is distributed under the terms of the Creative Commons Attribution 4.0 International License (http://crea tivecommons.org/licenses/by/4.0/), which permits unrestricted use, distribution, and reproduction in any medium, provided you give appropriate credit to the original author(s) and the source, provide a link to the Creative Commons license, and indicate if changes were made.

\section{References}

1. Ziemssen T (2009) Multiple sclerosis beyond EDSS: depression and fatigue. J Neurol Sci 277(Suppl 1):S37-S41

2. Rao SM, Leo GJ, Bernardin L, Unverzagt F (2009) Cognitive dysfunction in multiple sclerosis. I. Frequency, patterns, and prediction. Neurology 41:685-691

3. Rao SM, Leo GJ, Ellington L, Nauertz T, Bernardin L, Unverzagt F (1991) Cognitive dysfunction in multiple sclerosis. II. Impact on employment and social functioning. Neurology 41:692-696

4. Potagas C, Giogkaraki E, Koutsis G, Mandellos D, Tsirempolou E, Sfagos C, Vassilopoulos D (2008) Cognitive impairment in different MS subtypes and clinically isolated syndromes. J Neurol Sci 267:100-106

5. Feuillet L, Reuter F, Audoin B, Malikova I, Barrau K, Cherif AA, Pelletier J (2007) Early cognitive impairment in patients with clinically isolated syndrome suggestive of multiple sclerosis. Mult Scler 13:124-127

6. Pfleger CC, Flachs EM, Koch-Henriksen N (2010) Social consequences of multiple sclerosis (1): early pension and temporary unemployment $-\mathrm{a}$ historical prospective cohort study. Mult Scler 16:121-126

7. Kobelt G, Berg J, Lindgren P, Fredrikson S, Jönsson B (2006) Costs and quality of life of patients with multiple sclerosis in Europe. J Neurol Neurosurg Psychiatry 77:918-926

8. Orme M, Kerrigan J, Tyas D, Russell N, Nixon R (2007) The effect of disease, functional status, and relapses on the utility of people with multiple sclerosis in the UK. Value Health 10:54-60

9. Zwibel HL, Smrtka J (2011) Improving quality of life in multiple sclerosis: an unmet need. Am J Manag Care 17(Suppl 5):S139-S145

10. Aronson KJ (1997) Quality of life among persons with multiple sclerosis and their caregivers. Neurology 48:74-80

11. Gustavsson A, Svensson M, Jacobi F et al (2011) Cost of disorders of the brain in Europe 2010. Eur Neuropsychopharmacol 21:718-779

12. Kobelt G, Berg J, Atherly D, Hadjimichael O (2006) Costs and quality of life in multiple sclerosis: a cross-sectional study in the United States. Neurology 66:1696-1702

13. Sadovnick AD, Ebers GC, Wilson RW, Paty DW (1992) Life expectancy in patients attending multiple sclerosis clinics. Neurology 42:991-994

14. Ebers GC (2001) Natural history of multiple sclerosis. J Neurol Neurosurg Psychiatry 71(Suppl 2):ii16-ii19

15. Kingwell E, van der Kop M, Zhao Y, Shirani A, Zhu F, Oger J, Tremlett H (2012) Relative mortality and survival in multiple sclerosis: findings from British Columbia, Canada. J Neurol Neurosurg Psychiatry 83:61-66

16. Torkildsen NG, Lie SA, Aarseth JH, Nyland H, Myhr KM (2008) Survival and cause of death in multiple sclerosis: results from a 50-year follow-up in Western Norway. Mult Scler 14:1191-1198

17. Sadovnick AD, Eisen K, Ebers GC, Paty DW (1991) Cause of death in patients attending multiple sclerosis clinics. Neurology 41:1193-1196
18. Koch-Henriksen N, Brønnum-Hansen H, Stenager E (1998) Underlying cause of death in Danish patients with multiple sclerosis: results from the Danish Multiple Sclerosis Registry. J Neurol Neurosurg Psychiatry 65:56-59

19. Goodin DS, Reder AT, Ebers GC, Cutter G, Kremenchutzky M, Oger J, Langdon D, Rametta M, Beckmann K, DeSimone TM, Knappertz V (2012) Survival in MS: a randomized cohort study 21 years after the start of the pivotal IFN $\beta-1 b$ trial. Neurology 78:1315-1322

20. Río J, Comabella M, Montalban X (2011) Multiple sclerosis: current treatment algorithms. Curr Opin Neurol 24:230-237

21. Ziemssen T, de Stefano N, Sormani MP, Van Wijmeersch B, Wiendl H, Kieseier BC (2015) Optimizing therapy early in multiple sclerosis - an evidence-based view. Mult Scler Relat Disord 4:460-469

22. Tintoré M (2007) Early MS treatment. Int MS J 14:5-10

23. Trapp BD, Bö L, Mörk S, Chang A (1999) Pathogenesis of tissue injury in MS lesions. J Neuroimmunol 98:49-56

24. Trapp BD, Nave KA (2008) Multiple sclerosis: an immune or neurodegenerative disorder? Annu Rev Neurosci 31:247-269

25. Trapp BD, Peterson J, Ransohoff RM, Rudick R, Mörk S, Bö L (1998) Axonal transection in the lesions of multiple sclerosis. N Engl J Med 338:278-285

26. Hauser SL, Oksenberg JR (2006) The neurobiology of multiple sclerosis: genes, inflammation, and neurodegeneration. Neuron 52:61-76

27. Kuhlmann T, Lingfeld G, Bitsch A, Schuchardt J, Brück W (2002) Acute axonal damage in multiple sclerosis is most extensive in early disease stages and decreases over time. Brain 125:2202-2212

28. Ziemssen T (2004) Neuroprotection and glatiramer acetate: the possible role in the treatment of multiple sclerosis. Adv Exp Med Biol 541:111-134

29. Filippi M, Rocca MA (2007) Conventional MRI in multiple sclerosis. J Neuroimaging 17(Suppl 1):3S-9S

30. Rocca MA, Mezzapesa DM, Falini A, Ghezzi A, Martinelli V, Scotti G, Comi G, Filippi M (2003) Evidence for axonal pathology and adaptive cortical reorganization in patients at presentation with clinically isolated syndromes suggestive of multiple sclerosis. Neuroimage 18:847-855

31. Rovira A, Auger C, Alonso J (2013) Magnetic resonance monitoring of lesion evolution in multiple sclerosis. Ther Adv Neurol Disord 6:298-310

32. Scalfari A, Neuhaus A, Degenhardt A, Rice GP, Muraro PA, Daumer M, Ebers GC (2010) The natural history of multiple sclerosis: a geographically based study 10: relapses and longterm disability. Brain 133:1914-1929

33. Leray E, Yaouanq J, Le Page E, Coustans M, Laplaud D, Oger J, Edan G (2010) Evidence for a two-stage disability progression in multiple sclerosis. Brain 133:1900-1913

34. Zivadinov R, Stosic M, Cox JL, Ramasamy DP, Dwyer MG (2008) The place of conventional MRI and newly emerging MRI techniques in monitoring different aspects of treatment outcome. J Neurol 255(Suppl 1):61-74

35. Barkhof F, Calabresi PA, Miller DH, Reingold SC (2009) Imaging outcomes for neuroprotection and repair in multiple sclerosis trials. Nat Rev Neurol 5:256-266

36. Zivadinov R, Reder AT, Filippi M et al (2008) Mechanisms of action of disease-modifying agents and brain volume changes in multiple sclerosis. Neurology 71:136-144

37. Radue EW, Bendfeldt K, Mueller-Lenke N, Magon S, Sprenger $\mathrm{T}$ (2013) Brain atrophy: an in vivo measure of disease activity in multiple sclerosis. Swiss Med Wkly 143:w13887

38. De Stefano N, Giorgio A, Battaglini M et al (2010) Assessing brain atrophy rates in a large population of untreated multiple sclerosis subtypes. Neurology 74:1868-1876 
39. Simon JH (2006) Brain atrophy in multiple sclerosis: what we know and would like to know. Mult Scler 12:679-687

40. Minneboo A, Jasperse B, Barkhof F, Uitdehaag BM, Knol DL, de Groot V, Polman CH, Castelijns JA (2008) Predicting short-term disability progression in early multiple sclerosis: added value of MRI parameters. J Neurol Neurosurg Psychiatry 79:917-923

41. Fisher E, Rudick RA, Simon JH, Cutter G, Baier M, Lee JC, Miller D, Weinstock-Guttman B, Mass MK, Dougherty DS, Simonian NA (2002) Eight-year follow-up study of brain atrophy in patients with MS. Neurology 59:1412-1420

42. Bermel RA, Bakshi R (2006) The measurement and clinical relevance of brain atrophy in multiple sclerosis. Lancet Neurol 5:158-170

43. Tedeschi G, Lavorgna L, Russo P et al (2005) Brain atrophy and lesion load in a large population of patients with multiple sclerosis. Neurology 65:280-285

44. Fisniku LK, Chard DT, Jackson JS, Anderson VM, Altmann DR, Miszkiel KA, Thompson AJ, Miller DH (2008) Gray matter atrophy is related to long-term disability in multiple sclerosis. Ann Neurol 64:247-254

45. Fischer MT, Wimmer I, Höftberger R et al (2013) Diseasespecific molecular events in cortical multiple sclerosis lesions. Brain 136:1799-1815

46. Popescu V, Agosta F, Hulst HE et al (2013) Brain atrophy and lesion load predict long term disability in multiple sclerosis. J Neurol Neurosurg Psychiatry 84:1082-1091

47. Sormani MP, Arnold DL, De Stefano N (2014) Treatment effect on brain atrophy correlates with treatment effect on disability in multiple sclerosis. Ann Neurol 75:43-49

48. Vidal-Jordana A, Sastre-Garriga J, Rovira A, Montalban X (2015) Treating relapsing-remitting multiple sclerosis: therapy effects on brain atrophy. J Neurol 262(12):2617-26

49. Rudick RA, Fisher E, Lee JC, Duda JT, Simon J (2000) Brain atrophy in relapsing multiple sclerosis: relationship to relapses, EDSS, and treatment with interferon beta-1a. Mult Scler 6:365-372

50. Hardmeier M, Wagenpfeil S, Freitag P et al (2005) Rate of brain atrophy in relapsing MS decreases during treatment with IFNbeta-1a. Neurology 64:236-240

51. Kappos L, Traboulsee A, Constantinescu C et al (2006) Longterm subcutaneous interferon beta-1a therapy in patients with relapsing-remitting MS. Neurology 67:944-953

52. Ge Y, Grossman RI, Udupa JK et al (2000) Glatiramer acetate (Copaxone) treatment in relapsing-remitting MS: quantitative MR assessment. Neurology 54:813-817

53. Rovaris M, Comi G, Rocca MA et al (2001) Short-term brain volume change in relapsing-remitting multiple sclerosis: effect of glatiramer acetate and implications. Brain 124:1803-1812

54. Sormani MP, Rovaris M, Valsasina P, Wolinsky JS, Comi G, Filippi M (2004) Measurement error of two different techniques for brain atrophy assessment in multiple sclerosis. Neurology 62:1432-1434

55. Rovaris M, Comi G, Rocca MA et al (2007) Long-term followup of patients treated with glatiramer acetate: a multicentre, multinational extension of the European/Canadian double-blind, placebo-controlled, MRI-monitored trial. Mult Scler 13:502-508

56. Kappos L, Radue EW, O'Connor P et al (2010) A placebocontrolled trial of oral fingolimod in relapsing multiple sclerosis. N Engl J Med 362:387-401

57. Cohen JA, Barkhof F, Comi G et al (2010) Oral fingolimod or intramuscular interferon for relapsing multiple sclerosis. $\mathrm{N}$ Engl J Med 362:402-415

58. Calabresi PA, Radue EW, Goodin D et al (2014) Safety and efficacy of fingolimod in patients with relapsing-remitting multiple sclerosis (FREEDOMS II): a double-blind, randomised, placebo-controlled, phase 3 trial. Lancet Neurol 13:545-556

59. Arnold DL, Gold R, Kappos L et al (2014) Effects of delayedrelease dimethyl fumarate on MRI measures in the Phase 3 DEFINE study. J Neurol 261:1794-1802

60. Miller DH, Fox RJ, Phillips JT et al (2015) Effects of delayedrelease dimethyl fumarate on MRI measures in the phase 3 CONFIRM study. Neurology 84:1145-1152

61. Miller DH, Soon D, Fernando KT et al (2007) MRI outcomes in a placebo-controlled trial of natalizumab in relapsing MS. Neurology 68:1390-1401

62. Radue EW, Stuart WH, Calabresi PA (2010) Natalizumab plus interferon beta-1a reduces lesion formation in relapsing multiple sclerosis. J Neurol Sci 292:28-35

63. O'Connor P, Wolinsky JS, Confavreux C et al (2011) Randomized trial of oral teriflunomide for relapsing multiple sclerosis. N Engl J Med 365:1293-1303

64. Comi G, Jeffery D, Kappos L et al (2012) Placebo-controlled trial of oral laquinimod for multiple sclerosis. N Engl J Med 366:1000-1009

65. Vollmer TL, Sorensen PS, Selmaj K et al (2014) A randomized placebo-controlled phase III trial of oral laquinimod for multiple sclerosis. J Neurol 261:773-783

66. Mikol DD, Barkhof F, Chang P et al (2008) Comparison of subcutaneous interferon beta-1a with glatiramer acetate in patients with relapsing multiple sclerosis (the REbif vs Glatiramer Acetate in Relapsing MS Disease [REGARD] study): a multicentre, randomised, parallel, open-label trial. Lancet Neurol 7:903-914

67. O'Connor P, Filippi M, Arnason B et al (2009) 250 microg or 500 microg interferon beta- $1 \mathrm{~b}$ versus $20 \mathrm{mg}$ glatiramer acetate in relapsing-remitting multiple sclerosis: a prospective, randomised, multicentre study. Lancet Neurol 8:889-897

68. Lublin FD, Cofield SS, Cutter GR et al (2013) Randomized study combining interferon and glatiramer acetate in multiple sclerosis. Ann Neurol 73:327-340

69. Cohen JA, Coles AJ, Arnold DL et al (2012) Alemtuzumab versus interferon beta $1 \mathrm{a}$ as first-line treatment for patients with relapsing-remitting multiple sclerosis: a randomised controlled phase 3 trial. Lancet 380:1819-1828

70. Coles AJ, Twyman CL, Arnold DL et al (2012) Alemtuzumab for patients with relapsing multiple sclerosis after diseasemodifying therapy: a randomised controlled phase 3 trial. Lancet 380:1829-1839

71. Rudick RA, Fisher E, Lee JC, Simon J, Jacobs L (1999) Use of the brain parenchymal fraction to measure whole brain atrophy in relapsing-remitting MS. Multiple Sclerosis Collaborative Research Group. Neurology 53:1698-1704

72. Filippi M, Rovaris M, Inglese M, Barkhof F, De Stefano N, Smith S, Comi G (2004) Interferon beta-1a for brain tissue loss in patients at presentation with syndromes suggestive of multiple sclerosis: a randomised, double-blind, placebo-controlled trial. Lancet 364:1489-1496

73. Kappos L, Freedman MS, Polman CH et al (2009) Long-term effect of early treatment with interferon beta- $1 \mathrm{~b}$ after a first clinical event suggestive of multiple sclerosis: 5-year active treatment extension of the phase 3 BENEFIT trial. Lancet Neurol 8:987-997

74. Molyneux PD, Kappos L, Polman C, Pozzilli C, Barkhof F, Filippi M, Yousry T, Hahn D, Wagner K, Ghazi M, Beckmann K, Dahlke F, Losseff N, Barker GJ, Thompson AJ, Miller DH (2000) The effect of interferon beta-1b treatment on MRI measures of cerebral atrophy in secondary progressive multiple sclerosis. European Study Group on Interferon beta-1b in secondary progressive multiple sclerosis. Brain 123:2256-2263 
75. Comi G, Martinelli V, Rodegher M et al (2013) Effects of early treatment with glatiramer acetate in patients with clinically isolated syndrome. Mult Scler 19:1074-1083

76. Vidal-Jordana A, Sastre-Garriga J, Pérez-Miralles F et al (2013) Early brain pseudoatrophy while on natalizumab therapy is due to white matter volume changes. Mult Scler 19:1175-1181

77. Barkhof F, Hulst HE, Drulovic J, Uitdehaag BM, Matsuda K, Landin R, MN166-001 Investigators (2010) Ibudilast in relapsing-remitting multiple sclerosis: a neuroprotectant? Neurology 74:1033-1040

78. De Stefano N, Airas L, Grigoriadis N et al (2014) Clinical relevance of brain volume measures in multiple sclerosis. CNS Drugs 28:147-156

79. Barkhof F, Simon JH, Fazekas F et al (2011) MRI monitoring of immunomodulation in relapse-onset multiple sclerosis trials. Nat Rev Neurol 8:13-21

80. Zivadinov R, Havrdová E, Bergsland N et al (2013) Thalamic atrophy is associated with development of clinically definite multiple sclerosis. Radiology 268:831-841

81. Yaldizli Ö, Penner IK, Frontzek K (2014) The relationship between total and regional corpus callosum atrophy, cognitive impairment and fatigue in multiple sclerosis patients. Mult Scler 20:356-364

82. Carrá A, Onaha P, Luetic G et al (2008) Therapeutic outcome 3 years after switching of immunomodulatory therapies in patients with relapsing-remitting multiple sclerosis in Argentina. Eur J Neurol 15:386-393

83. Cohen JA, Reingold SC, Polman CH, Wolinsky JS, International Advisory Committee on Clinical Trials in Multiple Sclerosis (2012) Disability outcome measures in multiple sclerosis clinical trials: current status and future prospects. Lancet Neurol 11:467-476

84. Schäffler N, Schönberg P, Stephan J, Stellmann JP, Gold SM, Heesen C (2013) Comparison of patient-reported outcome measures in multiple sclerosis. Acta Neurol Scand 128:114-121

85. Multiple Sclerosis Therapy Consensus Group (MSTCG), Wiendl H, Toyka KV, Rieckmann P, Gold R, Hartung HP, Hohlfeld R (2008) Basic and escalating immunomodulatory treatments in multiple sclerosis: current therapeutic recommendations. J Neurol 255:1449-1463

86. Fernández O, García-Merino JA, Arroyo R et al (2012) Spanish consensus on the use of natalizumab (Tysabri $\left.\left({ }^{(}\right)\right)-2011$. Neurologia 27:432-441

87. Kieseier BC, Stüve O (2011) A critical appraisal of treatment decisions in multiple sclerosis-old versus new. Nat Rev Neurol $7: 255-262$

88. Giovannoni G, Turner B, Gnanapavan S, Offiah C, Schmierer K, Marta M (2015) Is it time to target no evident disease activity (NEDA) in multiple sclerosis? Mult Scler Relat Disord 4:329-333

89. Rotstein DL, Healy BC, Malik MT, Chitnis T, Weiner HL (2015) Evaluation of no evidence of disease activity in a 7-year longitudinal multiple sclerosis cohort. JAMA Neurol 72:152-158

90. Stangel M, Penner IK, Kallmann BA, Lukas C, Kieseier BC (2015) Towards the implementation of "no evidence of disease activity' in multiple sclerosis treatment: the multiple sclerosis decision model. Ther Adv Neurol Disord 8:3-13

91. Pérez-Miralles FC, Sastre-Garriga J, Vidal-Jordana A et al (2015) Predictive value of early brain atrophy on response in patients treated with interferon $\beta$. Neurol Neuroimmunol Neuroinflamm 2(4):e132

92. Kappos L, De Stefano N, Freedman MS et al (2015) Inclusion of brain volume loss in a revised measure of 'no evidence of disease activity' (NEDA-4) in relapsing-remitting multiple sclerosis. Mult Scler J (in press)
93. Arnold DL, Li D, Hohel M et al (2015) Evolving role of MRI in optimizing the treatment of multiple sclerosis: Canadian Consensus recommendations. Mult Scler J 1:1-9

94. Kappos L, Freedman MS, Polman CH et al (2007) Effect of early versus delayed interferon beta- $1 b$ treatment on disability after a first clinical event suggestive of multiple sclerosis: a 3-year follow-up analysis of the BENEFIT study. Lancet 370:389-397

95. Jacobs LD, Beck RW, Simon JH, Kinkel RP, Brownscheidle CM, Murray TJ, Simonian NA, Slasor PJ, Sandrock AW (2000) Intramuscular interferon beta-1a therapy initiated during a first demyelinating event in multiple sclerosis. CHAMPS Study Group. N Engl J Med 343:898-904

96. Kinkel RP, Kollman C, O'Connor P et al IM interferon beta-1a delays definite multiple sclerosis 5 years after a first demyelinating event. Neurology 66(5):678-684

97. Kinkel RP, Dontchev M, Kollman C, Skaramagas TT, O'Connor PW, Simon JH, Controlled High-Risk Avonex Multiple Sclerosis Prevention Study in Ongoing Neurological Surveillance Investigators (2012) Association between immediate initiation of intramuscular interferon beta- $1 \mathrm{a}$ at the time of a clinically isolated syndrome and long-term outcomes: a 10-year follow-up of the Controlled High-Risk Avonex Multiple Sclerosis Prevention Study in Ongoing Neurological Surveillance. Arch Neurol 69:183-190

98. Comi G, De Stefano N, Freedman MS et al (2012) Comparison of two dosing frequencies of subcutaneous interferon beta-1a in patients with a first clinical demyelinating event suggestive of multiple sclerosis (REFLEX): a phase 3 randomised controlled trial. Lancet Neurol 11:33-41

99. De Stefano N, Comi G, Kappos L et al (2013) Efficacy of subcutaneous interferon $\beta$-1a on MRI outcomes in a randomised controlled trial of patients with clinically isolated syndromes. J Neurol Neurosurg Psychiatry 85:647-653

100. Comi G, Martinelli V, Rodegher M et al (2009) Effect of glatiramer acetate on conversion to clinically definite multiple sclerosis in patients with clinically isolated syndrome (PreCISe study): a randomised, double-blind, placebo-controlled trial. Lancet 374:1503-1511

101. Miller AE, Wolinsky JS, Kappos L, Comi G, Freedman MS, Olsson TP, Bauer D, Benamor M, Truffinet P, O'Connor PW, TOPIC Study Group (2014) Oral teriflunomide for patients with a first clinical episode suggestive of multiple sclerosis (TOPIC): a randomised, double-blind, placebo-controlled, phase 3 trial. Lancet Neurol 13:977-986

102. Coles AJ, Cox A, Le Page E, Jones J, Trip SA, Deans J, Seaman S, Miller DH, Hale G, Waldmann H, Compston DA (2006) The window of therapeutic opportunity in multiple sclerosis: evidence from monoclonal antibody therapy. J Neurol 253:98-108

103. Kappos L, O'Connor P, Radue EW, Polman C, Hohlfeld R, Selmaj K, Ritter S, Schlosshauer R, von Rosenstiel P, ZhangAuberson L, Francis G (2015) Long-term effects of fingolimod in multiple sclerosis: the randomized FREEDOMS extension trial. Neurology 84:1582-1591

104. Bermel RA, You X, Foulds P, Hyde R, Simon JH, Fisher E, Rudick RA (2013) Predictors of long-term outcome in multiple sclerosis patients treated with interferon $\beta$. Ann Neurol 73:95-103

105. Río J, Castilló J, Rovira A et al (2009) Measures in the first year of therapy predict the response to interferon beta in MS. Mult Scler 15:848-853

106. Río J, Rovira A, Tintoré M, Huerga E, Nos C, Tellez N, Tur C, Comabella M, Montalban X (2008) Relationship between MRI lesion activity and response to IFN-beta in relapsing-remitting multiple sclerosis patients. Mult Scler 14:479-484 
107. Prosperini L, Mancinelli CR, De Giglio L, De Angelis F, Barletta V, Pozzilli C (2014) Interferon beta failure predicted by EMA criteria or isolated MRI activity in multiple sclerosis. Mult Scler 20:566-576

108. Sormani MP, De Stefano N (2013) Defining and scoring response to IFN- $\beta$ in multiple sclerosis. Nat Rev Neurol 9:504-512

109. Sormani MP, Rio J, Tintorè $M$, Signori A, Li D, Cornelisse $\mathrm{P}$, Stubinski B, Stromillo M, Montalban X, De Stefano N (2013) Scoring treatment response in patients with relapsing multiple sclerosis. Mult Scler 19:605-612

110. Sormani M, Signori A, Stromillo M, De Stefano N (2013) Refining response to treatment as defined by the Modified Rio Score. Mult Scler 19:1246-1247

111. Goodin DS, Traboulsee A, Knappertz V, Reder AT, Li D, Langdon D, Wolf C, Beckmann K, Konieczny A, Ebers GC, 16-Year Long Term Follow-up Study Investigators (2012) Relationship between early clinical characteristics and long term disability outcomes: 16 year cohort study (follow-up) of the pivotal interferon $\beta-1 b$ trial in multiple sclerosis. J Neurol Neurosurg Psychiatry 83:282-287

112. Caon C (2009) Maximising therapeutic outcomes in patients failing on current therapy. J Neurol Sci 277(Suppl 1):S33-S36

113. Castillo-Trivino T, Mowry EM, Gajofatto A et al (2011) Switching multiple sclerosis patients with breakthrough disease to second-line therapy. PLoS One 6:e16664

114. Gajofatto A, Bacchetti P, Grimes B, High A, Waubant E (2009) Switching first-line disease-modifying therapy after failure: impact on the course of relapsing-remitting multiple sclerosis. Mult Scler 15:50-58

115. Limmroth V, Malessa R, Zettl UK et al (2007) Quality Assessment in Multiple Sclerosis Therapy (QUASIMS): a comparison of interferon beta therapies for relapsing-remitting multiple sclerosis. J Neurol 254:67-77

116. Prosperini L, Borriello G, De Giglio L, Leonardi L, Barletta V, Pozzilli C (2011) Management of breakthrough disease in patients with multiple sclerosis: when an increasing of Interferon beta dose should be effective? BMC Neurol 11:26

117. Coles AJ, Twyman CL, Arnold DL et al (2012) Alemtuzumab for patients with relapsing multiple sclerosis after diseasemodifying therapy: a randomised controlled phase 3 trial. Lancet 380:1829-1839

118. Khatri B, Barkhof F, Comi G et al (2011) Comparison of fingolimod with interferon beta-1a in relapsing-remitting multiple sclerosis: a randomised extension of the TRANSFORMS study. Lancet Neurol 10:520-529

119. Ziemssen T, Kern R, Cornelissen C (2015) The PANGAEA study design - a prospective, multicenter, non-interventional, long-term study on fingolimod for the treatment of multiple sclerosis in daily practice. BMC Neurol 15:93

120. Ziemssen T, Kempcke R, Eulitz M, Großmann L, Suhrbier A, Thomas K, Schultheiss T (2013) Multiple sclerosis documentation system (MSDS): moving from documentation to management of MS patients. J Neural Transm 120(Suppl 1):61-66 